\title{
Detecção, controle e prevenção de fotobacteriose em cultivo de bijupirá
}

\author{
Eduardo Luiz Tavares Gonçalves(1), Eduardo Gomes Sanches(2), \\ Maurício Laterça Martins ${ }^{(1)}$ e Monica Yumi Tsuzuki ${ }^{(1)}$
}

\begin{abstract}
(1)Universidade Federal de Santa Catarina,Admar Gonzaga, no1.346, CEP88040-900 Florianópolis, SC, Brasil.E-mail: eltgoncalves@gmail.com, mlaterca@ufsc.br, monica.tsuzuki@ufsc.br (2)Instituto de Pesca, Estrada Professor Joaquim Lauro Monte Claro Neto, № 2.275, Praia do Itaguá, CEP 11680-000 Ubatuba, SP, Brasil. E-mail: esanches@pesca.sp.gov.br
\end{abstract}

Resumo - O objetivo deste trabalho foi analisar a detecção, o controle e a prevenção de fotobacteriose em cultivo de bijupirá. Essa doença é causada pela bactéria Photobacterium damselae, que, juntamente com outros fatores, pode estar sendo responsável pela estagnação no crescimento da produção nacional de bijupirá (Rachycentron canadum). Essa bactéria é considerada um dos principais patógenos de peixes marinhos cultivados, tendo sido responsável por importantes prejuízos econômicos em diversos países. No Brasil, essa bactéria ainda não recebeu a devida importância, apesar de já ter sido detectada como causadora de mortalidades nos cultivos de bijupirá. Photobacterium damselae possui duas subespécies, piscicida e damselae, que podem ser consideradas ameaças sanitárias, respectivamente, em relação à atividade econômica da piscicultura marinha e em relação à saúde humana. Neste trabalho, são apresentadas algumas estratégias de deteç̧ão, controle e prevenção. Enfatiza-se, também, a necessidade de um melhor acompanhamento sanitário nos cultivos de bijupirá e a importância da vacinação contra esse patógeno.

Termos para indexação: Photobacterium damselae, Rachycentron canadum, aquicultura, piscicultura marinha, sanidade animal, zoonose.

\section{Detection, control, and prevention of photobacteriosis in cobia culture in Brazil}

\begin{abstract}
The objective of this work was to analyse the detection, control, and prevention of photobacteriosis in cobia culture. This disease is caused by Photobacterium damselae bacterium, which, along with other factors, might be responsible for the stagnation in the development of national cobia (Rachycentron canadum) culture. This bacterium is considered one of the most important pathogens in marine fish culture, and it was responsible for major economic losses in a variety of countries. In Brazil, this bacterium has not yet getten proper attention, even though it was shown to have caused mortality in several cultured cobia fish. Photobacterium damselae has two subspecies, piscicida and damselae, which may be considered sanitary threats both to marine aquaculture economic activities and to human health, respectively. This paper presents some detection, control, and prevention strategies. It also emphasizes the need for a better sanitary control in cobia culture and the importance of vaccination against this pathogen.
\end{abstract}

Index terms: Photobacterium damselae, Rachycentron canadum, aquaculture, marine fish culture, animal health, zoonosis.

\section{Introdução}

A piscicultura marinha no Brasil tem crescido nos últimos anos (Cavalli \& Hamilton, 2009). A dificuldade da obtenção de formas jovens, que era o principal gargalo para a atividade no Brasil, vem sendo solucionada com a adoção de novas tecnologias (Sanches et al., 2013b). Para diversas espécies de peixes marinhos nativas e de elevado valor econômico, seus protocolos de reprodução e/ou de larvicultura foram estabelecidos, tais como o robalo-peva (Centropomus parallelus) (Alvarez-Lajonchère \& Tsuzuki, 2008), a garoupa-verdadeira (Epinephelus marginatus) (Sanches et al., 2009), o ariocó (Lutjanus synagris) (Sanches \& Cerqueira, 2010) e a cioba (Lutjanus analis) (Sanches et al., 2013a). Porém, o peixe marinho que tem, atualmente, despertado maior interesse para o cultivo tem sido o bijupirá (Rachycentron canadum).

O bijupirá, também conhecido como cobia, é uma espécie epipelágica, eurialina e euritérmica (Benetti et al., 2010), que apresenta comportamento migratório e ampla distribuição geográfica. É um peixe ativo, sem 
bexiga natatória (Resley et al., 2006), de hábito solitário (Van Der Velde et al., 2009), que forma agregados populacionais apenas durante o período de desova. Possui hábito alimentar carnívoro, alimentando-se de peixes bentônicos, crustáceos e lulas, e pode atingir mais de $2 \mathrm{~m}$ de comprimento e até $60 \mathrm{~kg}$ (Arendt et al., 2001; Holt et al., 2007).

As primeiras tentativas de cultivo dessa espécie começaram em Taiwan no início da década de 1990 e foram bem-sucedidas. $\mathrm{O}$ rápido crescimento apresentado pela espécie, podendo alcançar de 6 a $8 \mathrm{~kg}$ em um ano de cativeiro, estimulou o desenvolvimento da produção comercial e de tecnologias para a produção intensiva de juvenis em diversos países, como Estados Unidos, Porto Rico, Bahamas, Belize, México, República Dominicana e Panamá (Liao et al., 2004; Holt et al., 2007; Benetti et al., 2010), tendo atingido uma produção mundial de 43.395 toneladas em 2013 (The state of world fisheries and aquaculture, 2014).

A espécie ainda apresenta outras características favoráveis à aquicultura, entre elas: reprodução em cativeiro (Benetti et al., 2010); aceitação de dietas extrusadas (Craig et al., 2006); carne de excelente qualidade (Liao \& Leaño, 2007); e resposta positiva à vacinação (Lin et al., 2006). Tais vantagens, aliadas à facilidade na produção de formas jovens, têm estimulado muitos produtores a iniciar seus cultivos no Brasil.

Os resultados dos cultivos, entretanto, são prejudicados por elevadas taxas de mortalidade. $\mathrm{O}$ pioneirismo da atividade e a ausência de boas práticas de manejo, aliados à não utilização de dietas de alto valor nutricional, têm ocasionado baixas taxas de crescimento e o desenvolvimento de patógenos, o que inviabiliza economicamente a atividade (Kerber et al., 2011).

Apesar de o bijupirá aceitar dietas secas, na presente data ainda existe pouca base de informações para a formulação de dietas que atendam a todas as exigências nutricionais da espécie ao longo de toda a sua fase de crescimento até o peso de abate. Uma formulação adequada é importante não somente para que o animal possa expressar todo o seu potencial de crescimento, mas também para garantir a saúde deste, já que deficiências nutricionais acarretam uma série de doenças e aumentam a susceptibilidade a patógenos.

Para um crescimento saudável, bijupirá, assim como outros carnívoros marinhos, depende de rações com elevado teor proteico e lipídico, requer níveis adequados de ácido docosa-hexaenoico (DHA) na dieta (Trushenski et al., 2012), e necessita de suplementação com taurina (Salze et al., 2011), cuja ausência provoca redução na sobrevivência larval e síndrome do fígado verde em adultos (Goto et al., 2001; Salze et al., 2011). Muitas das rações comerciais disponíveis utilizadas pelos produtores são formuladas, originalmente, para peixes de água doce, portanto, deficientes nesses nutrientes. Além disso, a elevada necessidade de inclusão de farinha e óleo de peixe para formulação de dietas nutricionalmente adequadas para peixes marinhos resulta em dietas de elevado custo, preteridas pelos produtores.

Buscando contornar esses problemas, muitos produtores de bijupirá utilizam alimento fresco, como a sardinha (Sardinella brasiliensis) ou rejeito de pesca, para realizar a engorda da espécie, prática considerada controversa (Sampaio et al., 2011; Bunlipatanon et al., 2014), pois, além de ser uma possível fonte de eutrofização ambiental (Xu et al., 2007), pode ser uma importante fonte de contaminação com patógenos (Kim et al., 2007).

Neste contexto, os aspectos sanitários do cultivo tornam-se ainda mais relevantes, pois os peixes estão nutricionalmente debilitados e/ou expostos a condições de imunossupressão. Uma ampla gama de patógenos já foi relatada em espécimes de bijupirá ao redor do mundo, desde parasitos metazoários como Neobenedenia melleni MacCallum, 1927 (Monogenea: Capsalidae) (Kerber et al., 2011), protozoários como Amyloodinium ocellatum Brown, 1931 (Dinoflagellida) (McLean et al., 2008) e bactérias como Streptococcus iniae Pier \& Madin, 1976 e Photobacterium damselae Love et al., 1981 (Liao et al., 2004).

O objetivo deste trabalho foi analisar a detecção, controle e prevenção da bactéria Photobacterium damselae, um patógeno de especial relevância no cultivo de bijupirá, que desde 2011 tem sido registrado em cultivos brasileiros e que constitui uma importante ameaça sanitária à atividade de piscicultura marinha mundial.

\section{Caracterização do patógeno}

Photobacterium damselae é uma bactéria gram-negativa halófila, representante da família Photobacteriaceae, que possui duas subespécies, $P$. damselae subsp. piscicida e $P$. damselae subsp. 
damselae, cujos primeiros registros datam de 1963 (Snieszko et al., 1964) e 1981 (Love et al., 1981), respectivamente.

Inicialmente a espécie foi descrita como Vibrio damselae, por ter sido encontrada em peixes da família Pomacentridae, e ambas as subespécies já passaram por diversas redescrições taxonômicas, gerando dificuldade na obtenção de dados e uma subestimação do número de casos. Na literatura é possível encontrar trabalhos que utilizam as seguintes nomenclaturas: Photobacterium damselae, Photobacterium damsela, Vibrio damsela, Vibrio damselae, Pasteurella damselae, Pasteurella piscicida e Listonella damselae (Love et al., 1981; Fouz et al., 1993; Romalde, 2002; Labella et al., 2010; Hundenborn et al., 2013).

\section{Photobacterium damselae subsp. piscicida}

Photobacterium damselae subsp. piscicida é um patógeno responsável pela doença denominada fotobacteriose (também conhecida como pasteurelose ou pseudotuberculose), de grande importância na aquicultura por ser encontrado globalmente em espécies de peixes marinhos cultivados (Romalde, 2002; Ho et al., 2014), como R. canadum (Liao et al., 2004), olhete (Seriola quinqueradiata) (Romalde, 2002), pargo europeu (Sparus aurata) (Andreoni \& Magnani, 2014) e robalo europeu (Dicentrarchus labrax) (Korun \& Timur, 2005).

Ela é caracterizada por ser uma bactéria gram-negativa halofílica, imóvel, oxidase e catalase positiva, fermentativa sem produção de gás, que apresenta pleomorfismo, variando de cocoide a bastonetes longos dependendo do meio de cultura utilizado (Romalde, 2002; Roberts, 2012).

Esta bactéria apresenta crescimento ótimo entre 22,5 e $30^{\circ} \mathrm{C}$, podendo se desenvolver em uma faixa de temperatura que vai de 15 a $32,5^{\circ} \mathrm{C}$. Entretanto, devido ao seu lento crescimento, pode ocorrer dificuldade no seu isolamento do hospedeiro, devido à competição com bactérias de rápido crescimento (Romalde, 2002, 2014).

Esta subespécie forma um grupo homogêneo que se difere da $P$. damselae subsp. damselae, em especial nas seguintes características: ausência de atividade hemolítica em meio ágar sangue, e atividade negativa para redução do nitrato, urease, amilase e lípase (Romalde, 2002). Além disso, Rajan et al. (2003) relataram ausência de crescimento em meio ágar tiossulfato citrato sais de bile sacarose (TCBS).
É considerada um patógeno primário, de transmissão horizontal (entre peixes), capaz de sobreviver na água do mar e manter sua capacidade infecciosa (Magariños et al., 1994; Roberts, 2012), especialmente frente a peixes susceptíveis e imunodeprimidos. Além disso, uma vez que esta bactéria é frequentemente encontrada nas vísceras de peixes marinhos (McLean et al., 2008), é provável que o intestino seja uma importante porta de entrada do patógeno.

Os peixes afetados de forma crônica apresentam coloração enegrecida, letargia e diminuição do consumo. Enquanto animais afetados de forma aguda apresentam úlceras e erosões na superfície epidérmica da cabeça e nadadeiras. Internamente, os animais apresentam fígado pálido com volume aumentado e desenvolvem granulomas em órgãos como rim, baço e fígado, progredindo para um quadro de septicemia hemorrágica generalizada (Roberts, 2012).

\section{Photobacterium damselae subsp. damselae}

Photobacterium damselae subsp. damselae já foi isolada de diversas espécies marinhas cultivadas, como do robalo europeu (Dicentrarchus labrax), pargo europeu (Sparus aurata), corvina (Argyrosomus regius) e barramundi (Lates calcarifer) (Labella et al., 2010). É também uma bactéria gram-negativa halofílica e pleomórfica, geralmente com formato de bacilo, mas que, ao contrário $d a P$. damselae subsp. piscicida, apresenta elevada atividade hemolítica e cresce em meio TCBS (Austin \& Austin, 2007; Roberts, 2012).

É considerado um patógeno oportunista (Roberts, 2012), transmitido pela água (Fouz et al., 1998) e capaz de sobreviver aos mecanismos bactericidas do muco. Estima-se que exista uma distribuição sazonal na incidência da doença, com sua maior prevalência associada às temperaturas mais altas e ao estresse da reprodução (Austin, 2010). Além disso, também está associada a danos traumáticos (por exemplo, cortes e perfurações) (Roberts, 2012), sendo o tegumento uma via de entrada do patógeno (Austin \& Austin, 2007).

Os peixes afetados apresentam lesões ulcerativas no tegumento, em especial na região da nadadeira peitoral e pedúnculo caudal, que podem atingir até $2 \mathrm{~cm}$ de diâmetro (Austin, 2010). Na lesão ocorre lise do tecido muscular, e exames histopatológicos apontam para presença de dermatite ulcerativa granulomatosa, que se desenvolve em uma septicemia generalizada com extensa hemorragia (Austin \& Austin, 2007; Roberts, 
2012). Love et al. (1981) descreveram mortalidades após 4 dias em temperaturas entre 16,0 e $16,5^{\circ} \mathrm{C}$.

Um de seus principais mecanismos de virulência é a fosfolipase hemolítica, com a produção de damselysin (Dly) (Labella et al., 2010; Hundenborn et al., 2013). Porém, outros produtos extracelulares também estão envolvidos na citotoxicidade do patógeno (Austin, 2010). Segundo Fouz et al. (1993), a $\mathrm{DL}_{50}$ referente aos produtos extracelulares é de 0,02 a $0,43 \mu \mathrm{g} \mathrm{g}^{-1} \mathrm{de}$ proteína, e as mortalidades ocorrem entre 4 e 72 horas depois.

\section{Importância da $\boldsymbol{P}$. damselae no mundo}

Ambas as subespécies piscicida e damselae são importantes do ponto de vista sanitário e podem ser consideradas ameaças, respectivamente, em relação à atividade econômica e em relação à saúde humana.

Photobacterium damselae subsp. piscicida representa um dos maiores problemas no cultivo de bijupirá ao longo de todo o ciclo produtivo. Desde o início do cultivo desta espécie, em Taiwan, ela foi responsável por mortalidades massivas de até $80 \%$ e grandes prejuízos econômicos (Tung et al., 2000; Liao et al., 2004), que inviabilizaram o crescimento da atividade e estimularam o desenvolvimento de vacinas específicas (Lin et al., 2006; Ho et al., 2011).

Além disso, $P$. damselae subsp. piscicida é um patógeno amplamente distribuído, com registros de surtos em diversos países, incluindo: Taiwan (Liao et al., 2004); Japão (Toranzo et al., 2005); Turquia (Korun \& Timur, 2005); Espanha (Toranzo et al., 1991); e Portugal (Baptista et al., 1996).

Já a peculiaridade da subespécie damselae reside em sua capacidade de infectar outros grupos de animais, incluindo o ser humano, sendo, portanto, considerada uma zoonose (Roberts, 2012; Hundenborn et al., 2013), que, apesar de relativamente rara, com aproximadamente 20 casos de infecção humana relatados na literatura, costuma ser letal (Hundenborn et al., 2013).

A principal forma de infecção em humanos é por meio de lacerações ou perfurações durante a manipulação de peixes infectados; entretanto, a ingestão in natura de animais contaminados também é uma possível via de infecção (Hundenborn et al., 2013). Na grande maioria dos casos, o paciente desenvolve uma fasciite necrótica que evolui para óbito, às vezes em apenas 20 horas (Yamane et al., 2004). Nos poucos casos em que o paciente foi curado, em geral foi necessária amputação de um membro ou profundas remoções cirúrgicas de tecido (Barber \& Swygert, 2000).

A elevada taxa de mortalidade em humanos pode estar relacionada com a dificuldade dos profissionais de saúde na identificação correta do patógeno e na consequente aplicação de um tratamento adequado, uma vez que se trata de um patógeno incomum. E é possível que essa mesma questão implique um número muito maior de casos de infecções não identificadas ou não relatadas.

\section{Fotobacteriose no Brasil}

Estudos mais aprofundados sobre o impacto da fotobacteriose no Brasil e mesmo os dados de produção e comercialização de bijupirá ainda são escassos (Figueiredo et al., 2011). Esses autores identificaram a bactéria por método fenotípico, com a utilização do teste API $20 \mathrm{E}$ e, por método molecular, com sequenciamento do gene $16 \mathrm{~S}$ rRNA. Shimada et al. (2014) relataram a identificação molecular de uma das cepas da bactéria como $P$. damselae subsp. piscicida e descreveram os seguintes sinais clínicos nos animais infectados: letargia; úlceras nas nadadeiras; e fígados pálidos, com volume aumentado e com presença de nódulos granulomatosos com diâmetro entre $0,5 \mathrm{e}$ $2 \mathrm{~mm}$. Tais sinais correspondem àqueles normalmente relatados para fotobacteriose (Roberts, 2012).

Nascimento et al. (2014) também realizaram análises bacteriológicas, com base em fragmentos de órgãos internos, em 74 animais cultivados no Nordeste brasileiro, tendo obtido uma porcentagem de isolamento de $96 \%$ (71 peixes) de bactérias da família Vibrionaceae. Esses autores não relataram a presença de $P$. damselae, porém, utilizaram apenas ágar TCBS como meio de isolamento, o que restringiu a capacidade de isolar ambas as subespécies (Rajan et al., 2003; Korun \& Timur, 2005). Ainda assim, Nascimento et al. (2014) enfatizam que os exemplares de bijupirá analisados, embora aparentemente saudáveis, estão infectados com bactérias potencialmente patogênicas para peixes e humanos.

Dessa forma, é possível perceber que, apesar da inexistência de um registro oficial da doença, a fotobacteriose é uma realidade nos cultivos de bijupirá no Brasil, onde os produtores relatam redução no crescimento dos animais e mortalidades frequentes, cujo diagnóstico muitas vezes é mascarado pelo desconhecimento da doença. Essa situação torna-se 
ainda mais grave quando se levam em consideração as demais dificuldades experimentadas pelos produtores e que vêm efetivamente tornando inviável o desenvolvimento do cultivo de bijupirá no Brasil.

\section{Estratégias de deteç̧ão, controle e prevenção}

Em virtude da importância dessa doença, fazse necessária a utilização de técnicas adequadas de detecção e diagnóstico do patógeno. Entre os métodos mais apropriados destacam-se: sistemas miniaturizados como API 20E (padrão 2005004) (Andreoni \& Magnani, 2014), que é capaz de detectar a espécie, mas incapaz de diferenciar as subespécies; kits comerciais de testes imunoenzimáticos (Andreoni \& Magnani, 2014); e PCR multiplex dos genes 16S rRNA e ureC, capazes de diferenciar as subespécies piscicida e damselae (Andreoni \& Magnani, 2014).

Rajan et al. (2003) sugerem o uso combinado da detecção por PCR do gene 16S rRNA com a diferenciação em meio TCBS para discriminar as subespécies, uma vez que somente o gene $16 \mathrm{~S}$ rRNA é incapaz de diferenciar as subespécies desse patógeno (Osorio et al., 1999). Já Hundenborn et al. (2013) reportam sucesso na detecção e discriminação desse patógeno com o sistema MALDI-TOF de espectrofotometria de massa.

Além de serem capazes de detectar o patógeno, os países que experimentaram problemas sanitários com $P$. damselae tiveram que adotar medidas de controle e prevenção para conseguir conviver com a doença, em especial a utilização de vacinas (Romalde, 2002; Gudding \& Van Muiswinkel, 2013).

As primeiras tentativas de imunização contra P. damselae subsp. piscicida remontam ao final da década de 1980 e meados da década de 1990 (Romalde, 2014), e muito progresso ocorreu desde então, especialmente em virtude da uniformidade sorológica do patógeno, que facilitou o desenvolvimento de ferramentas de diagnóstico e também de vacinas específicas e eficientes (Thune et al., 2003; Romalde, 2014). Atualmente, existem vacinas específicas para $P$. damselae comercializadas por empresas internacionais (Gudding \& Van Muiswinkel, 2013), além de pesquisas para o desenvolvimento de novas vacinas de segunda geração que prometem ser ainda mais eficientes (Ho et al., 2011, 2014).

Lin et al. (2006) relataram produção de anticorpos uma semana após a injeção de $P$. damselae subsp. piscicida inativadas e taxas de sobrevivência após desafio superiores à $80 \%$ em bijupirá vacinados em comparação com animais não vacinados, que apresentaram sobrevivência inferior a $20 \%$. Os autores ainda apontaram $P$. damselae subsp. piscicida como a principal causa de mortalidade nos animais desafiados não vacinados, em comparação a outras bactérias contra as quais animais não vacinados foram desafiados.

Romalde (2014) discute que a melhor proteção contra fotobacteriose em Dicentrarchus labrax e Sparus aurata é obtida por meio de vacina com microrganismos inteiros inativados, enriquecida com produtos extracelulares, fornecida via imersão no estádio larval $(0,05 \mathrm{~g})$, seguida de uma segunda dose em juvenis (1-2 g) e de uma dose final fornecida via oral ou injeção já no local de engorda $(30-50$ g) (Le Breton, 2009).

Outras possíveis estratégias de controle e prevenção desse patógeno são o cultivo de bijupirá em baixas salinidades (Resley et al., 2006), uma vez que a bactéria é incapaz de sobreviver nessas condições, e a utilização do imunoestimulante levamisol (Leaño et al., 2003). O uso de antibióticos é uma opção, porém, devem ser analisados por um profissional qualificado e utilizados com cautela, pois podem induzir resistência bacteriana (Kim et al., 2008), contaminar o ambiente aquático (Lalumera et al., 2004) e nem sempre são efetivos (Romalde, 2002). Além disso, no Brasil ainda não há autorização do uso de antibióticos para piscicultura marinha.

\section{Considerações finais}

Dada a importância econômica e sanitária de ambas as subespécies dessa bactéria, é mandatório que haja um melhor acompanhamento sanitário nos cultivos de bijupirá (Rachycentron canadum), em especial na detecção do patógeno. Além disso, é fundamental a adoção de estratégias de controle da doença no Brasil, especialmente por meio da vacinação dos peixes, de acordo com o que já é praticado em outros países produtores. A utilização de vacinas, apesar de representar mais um custo para os produtores, pode ser uma solução economicamente vantajosa, especialmente considerando-se que, além de ser reduzida a mortalidade, os peixes poderão expressar melhor seu potencial de crescimento. 


\section{Referências}

ALVAREZ-LAJONCHÈRE, L.; TSUZUKI, M.Y. A review of methods for Centropomus spp. (snooks) aquaculture and recommendations for the establishment of their culture in Latin America. Aquaculture Research, v.39, p.684-700, 2008. DOI: 10.1111/j.1365-2109.2008.01921.x.

ANDREONI, F.; MAGNANI, M. Photobacteriosis: prevention and diagnosis. Journal of immunology Research, v.2014, article ID 793817, 2014. DOI: 10.1155/2014/793817.

ARENDT, M.; OLNEY, J.; LUCY, J. Stomach content analysis of cobia, Rachycentron canadum, from lower Chesapeake Bay. Fishery Bulletin, v.99, p.665-670, 2001.

AUSTIN, B. Vibrios as causal agents of zoonoses. Veterinary Microbiology, v.140, p.310-317, 2010. DOI: 10.1016/j. vetmic.2009.03.015.

AUSTIN, B.; AUSTIN, D.A. Bacterial fish pathogens. Dordrecht: Springer, 2007. 654p.

BAPTISTA, T.; ROMALDE, J.L.; TORANZO, A.E. First occurrence of pasteurellosis in Portugal affecting cultured gilthead seabream (Sparus aurata). Bulletin of the European Association of Fish Pathologists, v.16, p.92-95, 1996.

BARBER, G.R.; SWYGERT, J.S. Necrotizing fasciitis due to Photobacterium damselae in a man lashed by a stingray. The New England Journal of Medicine, v.342, p.824, 2000. DOI: 10.1056/ NEJM200003163421118.

BENETTI, D.; SARDENBERG, B.; HOENIG, R.; WELCH, A.; STIEGLITZ, J.; MIRALAO, S.; FARKAS, D.; BROWN, P.; JORY, D. Cobia (Rachycentron canadum) hatchery-to-market aquaculture technology: recent advances at the University of Miami Experimental Hatchery (UMEH). Revista Brasileira de Zootecnia, v.39, p.60-67, 2010. DOI: 10.1590/S1516-35982010001300008.

BUNLIPATANON, P.; SONGSEECHAN, N.; KONGKEO, H.; ABERY, N.W.; SILVA, S.S. de. Comparative efficacy of trash fish versus compounded commercial feeds in cage aquaculture of Asian seabass (Lates calcarifer) (Bloch) and tiger grouper (Epinephelus fuscoguttatus) (Forsskål). Aquaculture Research, v.45, p.373-388, 2014. DOI: 10.1111/j.1365-2109.2012.03234.x.

CAVALLI, R.O.; HAMILTON, S. Piscicultura marinha no Brasil com ênfase na produção do beijupirá. Revista Brasileira de Reprodução Animal Suplemento, v.6, p.64-69, 2009.

CRAIG, S.R.; SCHWARZ, M.H.; MCLEAN, E. Juvenile cobia (Rachycentron canadum) can utilize a wide range of protein and lipid levels without impacts on production characteristics. Aquaculture, v.261, p.384-391, 2006. DOI: 10.1016/j. aquaculture.2006.08.004.

FIGUEIREDO, H.C.P.; LEAL, C.A.G.; COSTA, F.A.A. Fotobacteriose em bijupirá cultivado: uma velha doença em uma produção nova. Revista Panorama da Aquicultura, n.125, p.30-35, 2011.

FOUZ, B.; BARJA, J.L.; AMARO, C.; RIVAS, C.; TORANZO, A.E. Toxicity of the extracellular products of Vibrio damsela isolated from diseased fish. Current Microbiology, v.27, p.341-347, 1993. DOI: 10.1007/BF01568958.
FOUZ, B.; TORANZO, A.E.; MARCO-NOALES, E.; AMARO, C. Survival of fish virulent strains of Photobacterium damselae subsp. damselae in seawater under starvation conditions. FEMS microbiology letters, v.168, p.181-186, 1998. DOI: 10.1111/ j.1574-6968.1998.tb13271.x.

GOTO, T.; TAKAGI, S.; ICHIKI, T.; SAKAI, T.; ENDO, M.; YOSHIDA, T.; UKAWA, M.; MURATA, H. Studies on the green liver in cultured red sea bream fed low level and non-fish meal diets: relationship between hepatic taurine and biliverdin levels. Fisheries Science, v.67, p.58-63, 2001. DOI: 10.1046/j.1444-29 06.2001.00199.x.

GUDDING, R.; VAN MUISWINKEL, W.B. A history of fish vaccination: science-based disease prevention in aquaculture. Fish \& Shellfish Immunology, v.35, p.1683-1688, 2013. DOI: 10.1016/j.fsi.2013.09.031.

HO, L.-P.; CHANG, C.-J.; LIU, H.-C.; YANG, H.-L.; LIN, J.H.-Y. Evaluating the protective efficacy of antigen combinations against Photobacterium damselae ssp. piscicida infections in cobia, Rachycentron canadum L. Journal of Fish Diseases, v.37, p.51-62, 2014. DOI: 10.1111/j.1365-2761.2012.01424.x.

HO, L.-P.; HAN-YOU LIN, J.; LIU, H.-C.; CHEN, H.-E.; CHEN, T.-Y.; YANG, H.-L. Identification of antigens for the development of a subunit vaccine against Photobacterium damselae ssp. piscicida. Fish \& Shellfish Immunology, v.30, p.412-419, 2011. DOI: $10.1016 /$ j.fsi.2010.11.029.

HOLT, G.J.; FAULK, C.K.; SCHWARZ, M.H. A review of the larviculture of cobia Rachycentron canadum, a warm water marine fish. Aquaculture, v.268, p.181-187, 2007. DOI: 10.1016/j. aquaculture.2007.04.039.

HUNDENBORN, J.; THURIG, S.; KOMMERELL, M.; HAAG, H.; NOLTE, O. Severe wound infection with Photobacterium damselae ssp. damselae and Vibrio harveyi, following a laceration injury in marine environment: a case report and review of the literature. Case Reports in Medicine, v.2013, p.610-632, 2013. DOI: $10.1155 / 2013 / 610632$.

KERBER, C.E.; SANCHES, E.G.; SANTIAGO, M.; LUQUE, J.L. First record of Neobenedenia melleni (Monogenea: Capsalidae) in sea-farmed cobia (Rachycentron canadum) in Brazil. Revista Brasileira de Parasitologia Veterinária, v.20, p.331-333, 2011. DOI: $10.1590 / \mathrm{S} 1984-29612011000400013$.

KIM, J.H.; GOMEZ, D.K.; CHORESCA JUNIOR, C.H.; PARK, S.C. Detection of major bacterial and viral pathogens in trash fish used to feed cultured flounder in Korea. Aquaculture, v.272, p.105-110, 2007. DOI: 10.1016/j.aquaculture.2007.09.008.

KIM, M.-J.; HIRONO, I.; KUROKAWA, K.; MAKI, T.; HAWKE, J.; KONDO, H.; SANTOS, M.D.; AOKI, T. Complete DNA sequence and analysis of the transferable multiple-drug resistance plasmids (R Plasmids) from Photobacterium damselae subsp. piscicida isolates collected in Japan and the United States. Antimicrobial Agents and Chemotherapy, v.52, p.606-611, 2008. DOI: 10.1128/AAC.01216-07.

KORUN, J.; TIMUR, G. The first pasteurellosis case in cultured Sea Bass (Dicentrarchus labrax L.) at low marine water temperatures in Turkey. Israeli Journal of Aquaculture, v.57, p.197-206, 2005. 
LABELLA, A.; SANCHEZ-MONTES, N.; BERBEL, C.; APARICIO, M.; CASTRO, D.; MANCHADO, M.; BORREGO, J.J. Toxicity of Photobacterium damselae subsp. damselae strains isolated from new cultured marine fish. Diseases of Aquatic Organisms, v.92, p.31-40, 2010. DOI: 10.3354/dao02275.

LALUMERA, G.M.; CALAMARI, D.; GALLI, P.; CASTIGLIONI, S.; CROSA, G.; FANELLI, R. Preliminary investigation on the environmental occurrence and effects of antibiotics used in aquaculture in Italy. Chemosphere, v.54, p.661-668, 2004. DOI: 10.1016/j.chemosphere.2003.08.001.

LE BRETON, A.D. Vaccines in mediterranean aquaculture: practice and needs. In: ROGERS, C.; BASURCO B. (Ed.). The use of veterinary drugs and vaccines in Mediterranean aquaculture. Zaragoza: CIHEAM, 2009. p.147-154.

LEAÑO, E.; GUO, J.J. ; CHANG, S.L. ; LIAO, I.C. Levamisole enhances non-specific immune response of Cobia (Rachycentron canadum) fingerlings. Journal of The Fisheries Society of Taiwan, v.30, p.321-330, 2003.

LIAO, I.C.; HUANG, T.-S.; TSAI, W.-S.; HSUEH, C.-M.; CHANG, S.-L.; LEAÑO, E.M. Cobia culture in Taiwan: current status and problems. Aquaculture, v.237, p.155- 165, 2004. DOI: 10.1016/j.aquaculture.2004.03.007.

LIAO, I.C.; LEAÑO, E.M. (Ed.). Cobia aquaculture: research, development and commercial production. Keelung: Asian Fisheries Society, 2007. 178p.

LIN, J.H.-Y.; CHEN, T.-Y.; CHEN, M.-S.; CHEN, H.-E.; CHOU, R.-L.; CHEN, T.-I.; SU, M.-S.; YANG, H.-L. Vaccination with three inactivated pathogens of cobia (Rachycentron canadum) stimulates protective immunity. Aquaculture, v. 255, p. 125-132, 2006. DOI: 10.1016/j.aquaculture.2005.12.005.

LOVE, M.; TEEBKEN-FISHER, D.; HOSE, J.E.; FARMER III, J.J.; HICKMAN, F.W.; FANNING, G.R. Vibrio damsela, a marine bacterium, causes skin ulcers on the damselfish Chromis. Science, v.214, p.1139-1140, 1981. DOI: 10.1126/science.214.4525.1139.

MAGARIÑOS, B.; ROMALDE, J.L.; BARJA, J.L.; TORANZO, A.E. Evidence for a dormant but infective stage of the fish pathogen Pasteurella piscicida. Applied and Environmental Microbiology, v.60, p.180-186, 1994.

MCLEAN, E.; SALZE, G.; CRAIG, S.R. Parasites, diseases and deformities of cobia. Ribarstvo, v.66, p.1-16, 2008.

NASCIMENTO, D.L.; BARROS, C.N.; SILVA, A.D.R.; GUIMARÃES, J.M.; PEDROSA, V.F.; MENDES, E.S. Bactérias potencialmente patogênicas isoladas de beijupirá (Rachycentron canadum) cultivadas em sistema offshore. Medicina Veterinária, v.8, p.12-21, 2014.

OSORIO, C.R.; COLLINS, M.D.; TORANZO, A.E.; BARJA, J.L.; ROMALDE, J.L. 16S rRNA gene sequence analysis of photobacterium damselae and nested PCR method for rapid detection of the causative agent of fish pasteurellosis. Applied and Environmental Microbiology, v.65, p.2942-2946, 1999.

PIER, G.B.; MADIN, S.H. Streptococcus iniae sp. nov., a beta-hemolytic streptococcus isolated from an Amazon freshwater dolphin, Inia geoffrensis. International Journal of Systematic and Evolutionary Microbiology, v.26, p.545-553, 1976.
RAJAN, P.R.; LIN, J.Y.-H.; HO, M.-S.; YANG, H.-L. Simple and rapid detection of Photobacterium damselae ssp. piscicida by a PCR technique and plating method. Journal of Applied Microbiology, v.95, p.1375-1380, 2003. DOI: 10.1046/j.1365-26 72.2003.02119.x.

RESLEY, M.J.; WEBB JR, K.A.; HOLT, G.J. Growth and survival of juvenile cobia, Rachycentron canadum, at different salinities in a recirculating aquaculture system. Aquaculture, v.253, p.398-407, 2006. DOI: 10.1016/j.aquaculture.2005.08.023.

ROBERTS, R.J. Fish pathology. $4^{\text {th }}$ ed. Oxford: Wiley-Blackwell, 2012. DOI: $10.1002 / 9781118222942$.

ROMALDE, J.L. Photobacterium damselae subsp. piscicida: an integrated view of a bacterial fish pathogen. International Microbiology, v.5, p.3-9, 2002.

ROMALDE, J.L. Vaccination against Photobacteriosis. In: GUDDING, R.; LILlEHAUG, A.; EVENSEN, Ø. (Ed.). Fish vaccination. Oxford: Wiley, 2014. DOI: 10.1002/9781118806913. ch17.

SALZE, G.; CRAIG, S.R.; SMITH, B.H.; SMITH, E.P.; MCLEAN, E. Morphological development of larval cobia Rachycentron canadum and the influence of dietary taurine supplementation. Journal of Fish Biology, v.78, p.1470-1491, 2011. DOI: 10.1111/j. 1095-8649.2011.02954.x.

SAMPAIO, L.A.; MOREIRA, C.B.; MIRANDA-FILHO, K.C.; ROMBENSO, A.N. Culture of cobia Rachycentron canadum (L) in near-shore cages off the Brazilian coast. Aquaculture Research, v.42, p.832-834, 2011. DOI: 10.1111/j.1365-2109.20 10.02770.x.

SANCHES, E.G.; CERQUEIRA, V.R. Refrigeração do sêmen do ariocó Lutjanus synagris. Boletim do Instituto de Pesca, v.36, p.293-305, 2010.

SANCHES, E.G.; OLIVEIRA, I. da R.; SERRALHEIRO, P.C. da S. Crioconservação do sêmen da garoupa-verdadeira Epinephelus marginatus (Lowe, 1834) (Teleostei, Serranidae). Boletim do Instituto de Pesca, v.35, p.389-399, 2009.

SANCHES, E.G.; OLIVEIRA, I.R.; SERRALHEIRO, P.C. da S.; CERQUEIRA, V.R. Cryopreservation of mutton snapper (Lutjanus analis) sperm. Anais da Academia Brasileira de Ciências, v.85, p.1083-1091, 2013a.

SANCHES, E.G.; TOSTA, G.A.M.; SOUZA-FILHO, J.J. Viabilidade econômica da produção de formas jovens de bijupirá (Rachycentron canadum). Boletim do Instituto de Pesca, v.39, p.15-26, 2013b.

SHIMADA, M.T.; CLAUDIANO, G.S.; ENGRACIA FILHO, J.R.; YUNIS, J.; MORAES, F.R.; MOREIRA, R.G.; MORAES, J.R.E. Hepatic steatosis in cage-reared young cobia, Rachycentron canadum (Linnaeus, 1766) in Brazil. Journal of Veterinary Science and Medical Diagnosis, v.3, p.2-5, 2014. DOI: 10.4172/2325-9590.1000137.

SNIESZKO, S.F.; BULLOCK, G.L.; HOLLIS, E.; BOONE, J.G. Pasteurella sp. from an epizootic of white perch (Roccus americanus) in Chesapeake Bay tidewater areas. Journal of Bacteriology, v 88, p.1814-1815, 1964. 
THE STATE of world fisheries and aquaculture: opportunities and challenges. Rome: Food and Agriculture Organization Fisheries Department, 2014. 243p.

THUNE, R.; FERNANDEZ, D.H.; HAWKE, J.P.; MILLER, R. Construction of a safe, stable, efficacious vaccine against Photobacterium damselae ssp. piscicida. Diseases of Aquatic Organisms, v.57, p.51-58, 2003. DOI: 10.3354/dao057051.

TORANZO, A.E.; BARREIRO, S.; CASAL, J.F.; FIGUERAS, A.; BARJA, J.L. Pasteurellosis in cultured gilthead seabream (Sparus aurata) - first report in spain. Aquaculture, v.99, p.1-15, 1991. DOI: 10.1016/0044-8486(91)90284-E.

TORANZO, A.E.; MAGARIÑOS, B.; ROMALDE, J.L. A review of the main bacterial fish diseases in mariculture systems. Aquaculture, v.246, p.37-61, 2005. DOI: 10.1016/j. aquaculture.2005.01.002.

TRUSHENSKI, J.; SCHWARZ, M.; BERGMAN, A.; ROMBENSO, A.; DELBOS, B. DHA is essential, EPA appears largely expendable, in meeting the $n-3$ long-chain polyunsaturated fatty acid requirements of juvenile cobia Rachycentron canadum. Aquaculture, v.326-329, p.81-89, 2012. DOI: 10.1016/j. aquaculture.2011.11.033.
TUNG, M.C.; CHANG, L.T.; TSAI, S.-S.; WANG, D.H. Mass mortality associated with Photobacterium damsela subsp. piscicida in sea-cage cultured cobia Rachycentron canadum (Linnaeus, 1776) in southern Taiwan. FA COA Aquaculture Series, n.1, p.133-145, 2000.

VAN DER VELDE, T.D.; GRIFFITHS, S.P.; FRY, G.C. Reproductive biology of the commercially and recreationally important cobia Rachycentron canadum in northeastern Australia. Fisheries Science, v.76, p.33-43, 2009. DOI: 10.1007/ s12562-009-0177-y.

XU, Z.; LIN, X.; LIN, Q.; YANG, Y.; WANG, Y. Nitrogen, phosphorus, and energy waste outputs of four marine cage-cultured fish fed with trash fish. Aquaculture, v.263, p.130-141, 2007. DOI: $10.1016 /$ j.aquaculture.2006.10.020.

YAMANE, K.; ASATO, J.; KAWADE, N.; TAKAHASHI, H.; KIMURA, B.; ARAKAWA, Y. Two cases of fatal necrotizing fasciitis caused by Photobacterium damselae in Japan. Journal of Clinical Microbiology, v.42, p.1370-1372, 2004. DOI: 10.1128/ JCM.42.3.1370-1372.2004.

Recebido em 28 de novembro de 2014 e aprovado em 18 de dezembro de 2015 